\title{
Pesquisa translacional na oftalmologia: o caminho para a medicina personalizada
}

\author{
Translactional research in ophthalmology: \\ the path to personalized medicine
}

Rubens Camargo Siqueira MD,PhD ${ }^{1,2}$

\begin{abstract}
RESUMO
A investigação científica é tradicionalmente dividida em duas categorias: a pesquisa básica e a pesquisa aplicada. A pesquisa básica é necessária para proporcionar o melhor entendimento do estado normal versus doença, mas não diretamente traduzindo esse conhecimento em aplicação clínica útil. A pesquisa translacional seria o avanço da ciência aplicado ao desenvolvimento de novos testes de diagnóstico, drogas e ou técnicas de intervenção junto às pacientes estabelecidos na compreensão do desenvolvimento da doença e sua progressão.

O principal objetivo da pesquisa translacional é integrar os avanços na biotecnologia, com ensaios clínicos, impulsionando a investigação da bancada ao leito

A evolução da pesquisa translacional na área de oftalmologia está construindo uma medicina de maior eficácia na prevenção e tratamento individualizado formando os ingredientes básicos da almejada medicina personalizada.

Este artigo descreve os conceitos básicos da pesquisa translacional e sua aplicação na oftalmologia.

Descritores: Pesquisa translacional; Células tronco; Terapia de genes; Pesquisa biomédica
\end{abstract}

\begin{abstract}
Scientific research is traditionally divided into two categories: basic research and applied research. Basic research is needed to provide a better understanding of disease, but not directly translating that knowledge into useful clinical application. Translational research would be the advancement of science applied to the development of new diagnostic tests, drugs and or intervention techniques for patients with established understanding of disease development and progression. bedside.

The main goal of translational research is to integrate advances in biotechnology, clinical trials, boosting the research bench to the

The evolution of translational research in the area of ophthalmology are building a medicine of greater effectiveness in the prevention and treatment individualized form the basic ingredients of the desired personalized medicine.

This paper describes the basic concepts of translational research and its application in ophthalmology.

Keywords:Translational research;Stem cell;Gene therapy; Biomedical research
\end{abstract}

\footnotetext{
${ }^{1}$ Centro de Pesquisa Rubens Siqueira (CPRS) - São José do Rio Preto (SP), Brasil;

${ }^{2}$ Faculdade de Medicina de Ribeirão Preto, Universidade de Sao Paulo (USP) - Ribeirão Preto (SP), Brasil.

Os autores declaram inexistir conflitos de interesse

Recebido para publicação em 27/6/2011 - Aceito para publicação em 16/8/2011
} 


\section{INTRODUÇÃO}

A investigação científica é tradicionalmente dividida em duas categorias: a pesquisa básica e a pesquisa aplicada. A pesquisa básica é necessária para proporcionar o melhor entendimento do estado normal versus doença, mas não diretamente traduzindo esse conhecimento em aplicação clínica útil. A pesquisa translacional seria o avanço da ciência aplicado ao desenvolvimento de novos testes de diagnóstico, drogas e ou técnicas de intervenção junto às pacientes estabelecidos na compreensão do desenvolvimento da doença e sua progressão $0^{(1)}$.

O principal objetivo da pesquisa translacional é integrar os avanços na biotecnologia, com ensaios clínicos, impulsionando a investigação da bancada ao leito

Observações de investigadores clínicos sobre a natureza e a progressão da doença direcionam à investigação científica de base. Pesquisadores usam amostras clínicas para o estudo do diagnóstico, da expressão de biomarcadores de doenças, das diferenças entre a condição normal e a doença e, a resposta à terapia. Os cientistas básicos, em seguida, fornecem aos clínicos novas estratégias de tratamento baseadas em dados de laboratório. Esse feedback constante promove a descoberta de biomarcadores de doenças e identifica alvos de drogas, resultando em um desenvolvimento mais racional de medicamentos, além de melhorar a eficácia dos agentes terapêuticos (Figura 1) ${ }^{(1-2,2,3)}$.

A pesquisa translacional também permite o desenvolvimento mais rápido de potenciais terapêuticos, reduzindo o tempo entre a identificação do alvo das drogas e opções terapêuticas clinicamente relevantes. Atualmente, a conclusão de todas as fases dos testes pré-clínicos e clínicos de uma única droga pode levar 7 a 12 anos, mas a grande quantidade de investigação translacional que está sendo realizada em todo o mundo é um sinal promissor para avanços mais rápidos em um futuro próximo ${ }^{(1)}$.

\section{A pesquisa translacional}

A pesquisa translacional é a base para a medicina translacional. É o processo que leva a medicina baseada em evidências para soluções sustentáveis para problemas de saúde pública ${ }^{(2)}$. Tem como objetivo melhorar a saúde e propiciar a longevidade das populações do mundo e depende basicamente do desenvolvimento de equipes de cientistas e estudiosos capazes de concentrar seus esforços para conseguir uma ligação das descobertas científicas básicas com a arena da investigação clínica (translação). Além de traduzir os resultados de ensaios clínicos em mudanças na prática clínica através de provas a partir das ciências sociais e políticas. ${ }^{(2)}$

A pesquisa translacional pode ser dividida em três fases:

\section{Fase 1 da pesquisa translacional}

A fase 1 da pesquisa translacional é um processo de pesquisa que explora as necessidades, desenvolve tratamentos potenciais em pesquisas laboratoriais básicos, e testes de segurança e eficácia. Isto é principalmente feito em ensaios clínicos randomizados. O conceito surgiu da investigação sobre a farmacoterapia e formaram a base inicial para a prática baseada em evidências e diretrizes clínicas, agora incorporada à medicina translacional. No caso de descoberta de drogas e de desenvolvimento, a investigação translacional normalmente se refere à translação da pesquisa realizada no laboratório e aplicação clinica desta terapia nos pacientes. Isso é muitas vezes chamado de "laboratório para o leito". Muitas empresas farmacêuticas estão construindo (fase 1) grupos de medicina translacional para facilitar a interação entre pesquisa básica e clínica, particularmente em ensaios clínicos. A avaliação clínica de terapias desenhadas de outras disciplinas (por exemplo, a psicologia, atividade física, nutricional) também pode ser incluída dentro da fase 1 da pesquisa translacional.

\section{Fase 2 da pesquisa translacional}

A pesquisa translacional na fase 2 examina as descobertas da ciência clínica, demonstrando a eficácia e a segurança dos tratamentos estabelecidos na fase 1 da pesquisa translacional quanto sua função, quando são aplicados na prática rotineira ${ }^{(3)}$. Assim, consiste no desenvolvimento e aplicação de novas tecnologias no ambiente do paciente em situações da vida real, onde fatores demográficos e prioridades concorrentes podem modificar as decisões clínicas e respostas ao tratamento. A pesquisa translacional na fase 2, portanto, informa diretrizes sobre necessidades, aceitabilidade, eficácia e eficiência de custos nos ambientes ecológicos e políticos para promover a captação para uma última gestão e utilização dos recursos. Portanto a pesquisa nessa fase desempenha um papel muito informativo, alimentando tanto as diretrizes sobre necessidades, aceitabilidade, efetividade e custo-eficiência quanto às políticas de saúde na promoção de ótimo manejo e uso de recursos. Particularmente no mundo moderno, em via de uma grande recessão econômica, essas necessidades devem desafiar o ambiente criado pelas perspectivas da restrita visão proporcionadas pelo ambiente exclusivo dos ensaios clínicos $^{(1,4)}$.

\section{Fase 3 da pesquisa translacional}

A fase 3 da pesquisa translacional adiciona informações necessárias para converter tratamentos e estratégias de prevenção, que já demonstraram sua efetividade e custo-eficácia na fase 2 , em bases para políticas governamentais mais rígidas e ao mesmo tempo amplas, baseadas em evidências. Essas políticas requerem diferentes tipos de processos de pesquisa para avaliar ambientes de interação mais complexa. Envolvem um processo de sustentabilidade que depende de abordagens que necessitam de contínuo refinamento e melhora metodológica ${ }^{(2)}$. Alcançar a sustentabilidade depende de provas a partir de duas frentes. Em primeiro lugar, as abordagens de circuito fechado de auditoria são necessárias dentro de Metodologia de Melhoria Contínua para refinar a intervenção. Lições podem ser aprendidas com sucesso de empreendimentos comerciais e de produto, que utilizam a pesquisa não-experimental multidisciplinar para informar melhorias incrementais ${ }^{(2)}$. Metodologia de melhoria contínua é conhecida como "kaizen" em japonês, onde se originou. Em segundo lugar, pesquisas são necessárias para obter provas para fazer alterações em múltiplos fatores ambientais e de política que irão reduzir a necessidade de financiamento para sustentar a intervenção.

\section{A medicina personalizada}

Medicina personalizada, como um termo, evoluiu para indicar que os resultados de várias formas de análise genômica são aplicados para adequar os cuidados médicos de um paciente individual com vantagens claras que complementam, mas não substituem a medicina clínica tradicional. Essas vantagens incluem a possibilidade de prever a susceptibilidade a doenças e programação de um tratamento preventivo profilático. Medicina personalizada também oferece o potencial para o diagnóstico da doença em um momento inicial permitindo o tratamento de forma mais eficaz quando as sequelas da doença podem ser amenizadas.

Existem imensas oportunidades de negócios para empresas que desenvolvam diagnósticos, medicamentos ou métodos para análise de dados. Várias escolas médicas no mundo têm desenvolvido institutos, programas ou currículos focados em medicina personalizada. Empresas foram formadas utilizando análises de marketing individual que se propõem a prever o risco de desenvolvimento de uma serie de doenças que vão des- 
de a doença de Alzheimer ou diabetes, a calvície de padrão masculino.

Múltiplos obstáculos devem ser superados para alcançar essas metas. Estes incluem desafios científicos, tais como a determinação de marcadores genéticos que têm o significado clínico, limitando os efeitos fora do alvo das terapias baseadas em genes, e realização de estudos clínicos para identificar variações genéticas que são correlacionados com uma resposta de drogas. Há também desafios políticos, tais como encontrar um nível de regulamentação para testes genéticos que tanto protege os pacientes e estimula a inovação. Para progredir,nos Estados Unidos o National Institutes of Health (NIH)e o Food and Drug Administration (FDA) irão investir no avanço da ciência translacional e sua regulamentação, definindo melhor as vias reguladoras para aprovação coordenada de diagnóstico e terapêutica, desenvolver abordagens baseadas no risco para o adequado exame de diagnóstico para avaliar com mais precisão a sua validade e utilidade clínica, e tornar as informações sobre os testes disponíveis.

A passagem de conceito para o uso clínico requer ciência básica, translacional, e regulamentar. Na ciência básica, estudos estão identificando muitas variações genéticas subjacentes e os riscos de ambas as doenças raras e comuns. Estes genes recémdescobertos, proteínas, e suas vias podem representar novos alvos terapêuticos poderosos, mas atualmente não há provas suficientes que suportem um investimento pesado do setor privado nesta área. Para preencher esse vazio, do NIH e o FDA irão desenvolver uma via mais integrada que conecta todas as etapas entre a identificação de um potencial alvo terapêutico por pesquisadores acadêmicos e da aprovação de uma terapia para uso clínico. Esta via irá incluir centros credenciados pelo NIH onde pesquisadores desenvolverão milhares de substâncias químicas para encontrar potenciais medicamentos, bem como parcerias público-privadas para ajudar a composição do produto e a sua disponibilidade comercial ${ }^{(4,5)}$.

\section{Pesquisa translacional na Oftalmologia}

A pesquisa translacional está invadindo todas as especialidades com a grande promessa de ser uma evolução da medicina baseada em evidências e com o objetivo de aproximarmos cada vez mais da medicina personalizada.

Em outras especialidades já estão utilizando o conceito da cirurgia genômica,ou seja,através da análise do perfil genético do paciente a decisão cirúrgica como principal alvo (por exemplo,uma retirada de tumor) são determinados com o mapeamento genético do paciente ${ }^{(6)}$.

$\mathrm{Na}$ oftalmologia observamos também grande avanço no caminho da medicina translacional.Abaixo são descritos alguns exemplos de pesquisa que utilizam este conceito e que certamente fará parte de nossa prática clínica em um futuro bem próximo.

\section{a) Análise e terapia genética na oftalmologia}

A era moderna da oftalmologia molecular começou em 1985 , com a descoberta do gene doretinoblastoma ${ }^{(6)}$. Desde então, centenas de outros genes que são responsáveis por uma grande variedade de doenças importantes foram descobertos, incluindo aqueles associados com a degeneração macular relacionada à idade (DMRI), glaucoma, catarata congênita, degeneraçãohereditária de fotorreceptores, distrofias da córnea, vitreorretinopatias e neuropatias ópticas. A descoberta de cada nova causa genética da doença oferece a possibilidade de usar a investigação molecular de amostras de DNA coletadas de pacientes individuais como um complemento ao diagnóstico clínico, prognóstico e aconselhamento. Além disso, as pessoas que são encontradas, levando conhecidas mutações causadoras de doenças podem ser envolvidas em ensaios clínicos de novas terapias ou cuidadosamente estudadas com uma variedade de instrumentos clínicos para explorar plenamente o comportamento da doença ao longo do tempo ${ }^{(7,8)}$. Amostras de pacientes que não possuem mutações em conhecidos genes causadores da doença também podem servir como um recurso valioso para os cientistas que buscam encontrar adicionais genes causadores da doença ${ }^{(9)}$.

A descoberta de que ABCA4 está envolvida no transporte de derivados da vitamina A de discos do segmento externo dos fotorreceptores levou à descoberta de que a vitamina $\mathrm{A} \mathrm{e}$ fenretinide podem inibir o acúmulo de lipofuscina em modelos animais da doença de Stargardt ${ }^{(10,11)}$. A identificação do papel do fator de crescimento endotelial vascular na neovascularização da coróide levou ao desenvolvimento de anticorpos terapêuticos (por exemplo, ranibizumab e bevacizumab) para o tratamento da DMRI exsudativa. Fatores de crescimento e agentes neuroprotetores também têm sido utilizados para reduzir a taxa de uma resposta apoptóticaconsequente a anormalidades celulares ocasionadas por defeito genético ${ }^{(12,13)}$. Nos últimos anos, a terapia genética de reposição, a terapia celular com uso de células-tronco e próteses de retina avançaram o limiar do uso clínico.

Mais de uma dúzia de doenças recessivas da retina têm sido tratadas com sucesso com a transferência de genes virais ou baseado em nanopartículas em modelos animais ${ }^{(14)}$. Por exemplo, uma forma molecular de amaurose congênita de Leber é causada pela falta da isomerase retinóide codificado por RPE65 e foi restaurado a visão em um modelo natural de cães desta doença utilizando um vetor viral adeno-associado para transferir uma versão normal de RPE65 para o epitélio pigmentado da retina ${ }^{(15)}$. Mais recentemente, três grupos diferentes têm estendido este trabalho para os seres huma$\operatorname{nos}^{(16-18)}$. Maguire et al. reportaram resultados em 12 pacientes que foram tratados com terapia de reposição genética. Eles observaram melhora visual em todos os 12 pacientes submetidos ao tratamento, com os maiores ganhos observados nos pacientes mais jovens ${ }^{(16)}$.

Recentemente foi lançado o Macula Risk (ArcticDx, Inc., Toronto, Canadá) que é um teste disponível comercialmente usado no prognóstico genético para pacientes diagnosticados com a DMRI precoce ou intermediária. Usando um algoritmo baseado na combinação completa de genes da DMRI e história de tabagismo, o teste genético identifica aqueles com maior probabilidade de progredir para DMRI avançada com perda de visão. A capacidade de identificar pacientes em risco permite que os médicos programem um plano de seguimento e tratamento mais adequado para cada paciente de forma individual

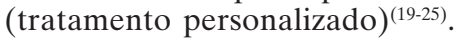

\section{Terapia com células tronco}

Vários tipos de células importantes no olho têm pouca ou nenhuma capacidade de regeneração endógena, e como resultado, a única opção de tratamento viável para pacientes com distúrbios hereditários que envolvem a perda de tais células é algum tipo de terapia de reposição de células. Embora a substituição de células altamente diferenciadas, como fotorreceptores, apresentem desafios, além disso uma série de experimentos recentes sugere que o uso de células-tronco para atingir tal objetivo pode ser viável ${ }^{(9)}$.

Tipos de células-tronco distintas foram estabelecidas a partir de embriões e identificadas nos tecidos fetais e do sangue do cordão umbilical (UCB), bem como em nichos específicos em tecidos adultos de muitos mamíferos e órgãos como a medula óssea (BM), cérebro, pele, olhos, coração, rins, pulmões, trato gastrointestinal, pâncreas, fígado, mama, ovários e próstata ${ }^{(26)}$.A terapia celular baseada no uso de células tronco foi testada em modelos animais para várias doenças, incluindo doenças neurodegenerativas, como doença de Parkinson, lesão medular, e esclerose múltipla. A substituição de neurônios perdidos que 
não são fisiologicamente substituídos é fundamental para o sucesso terapêutico. No olho, a degeneração das células neurais na retina é uma característica de tais doenças oculares generalizadas como relacionadas com a idade degeneração macular (DMRI) e retinose pigmentar (RP). Nestes casos, a perda de fotorreceptores que ocorre como um evento primário (RP) ou secundário à perda de epitélio pigmentado da retina (DMRI) pode levar à cegueira ${ }^{(26-28)}$.

Células-tronco $(\mathrm{CT})$ pode potencialmente ser utilizadas tanto para a neuroproteção como para a substituição celular. A injeção intravítrea de fatores neurotróficos retarda a degeneração de fotorreceptores em modelos de roedores de RP e perda RGC em modelos de glaucoma e nervo óptico (ON) e trato óptico (OT) trauma, mas o efeito pode ser temporário. Preparações de liberação lenta e abordagens de terapia genética para induzir as células da retina a secretar fatores neurotróficos são duas maneiras de induzir efeitos a longo prazo. Uma terceira opção é a utilização de células tronco como agentes de fornecimento em longo prazo, possivelmente encapsuladas em um dispositivo, porque muitas células troncos secretam neurotrofinas naturalmente ou podem ser geneticamente modificadas para fazê-lo ${ }^{(29,30)}$.

Recentemente, alguns relatos demonstraram a viabilidade clínica da administração intravítrea de células tronco derivadas da medula óssea em pacientes com doenças degenerativas da retina ${ }^{(31,32)}$. Mais recentemente, nosso grupo realizou uma fase prospectiva I do estudo para investigar a segurança da injeção intravítrea de células-tronco derivadas da medula óssea em pacientes com retinose pigmentar com resultados promissores ${ }^{(33)}$.

Em 2010, nos Estados Unidos, a FDAconcedeu a empresa Advanced Cell Technology, Inc. (células RPE ACT) autorizaçãopara iniciar seu estudo clínico de Fase 1/2 usando epitélio pigmentado da retina (EPR), derivado de células estaminais embrionárias humanas (hESCs) para tratar pacientes com distrofia macular deStargardt; em 2011 a empresa recebeu um parecer positivo do Comitê dos Medicamentos Órfãos (COMP) da Agência Européia do Medicamento (EMA) para designação desse produto como medicamento órfão para o tratamento da doença de Stargardt ${ }^{(34)}$.

Células-tronco (CT) mantém o equilíbrio entre as populações de células somáticas em vários tecidos e são responsáveis pela regeneração de órgãos. Os notáveis progressos da medicina regenerativa nos últimos anos indicam uma grande promessa para o uso de células tronco no tratamento de doençasoftalmológicas.

Pesquisas com células-tronco abriram outra vertente na investigação translacional.

A necessidade de usar o laboratório, biólogos e especialistas clínicos têm criado um ambiente multidisciplinar, uma característica da medicina translacional.

\section{Conclusão}

Medicina translacional tem sido descrita como a aplicação integrada de ferramentas inovadoras de farmacologia, biomarcadores, métodos clínicos, tecnologias clínicas e desenhos de estudo para melhorar a compreensão das doenças. Na medicina, investigação de translação oferece uma oportunidade para aplicar os resultados obtidos desde a pesquisa básica às aplicações clínicas.

A evolução da pesquisa translacional na área de oftalmologia está construindo uma medicina de maior eficácia na prevenção e tratamento individualizado formando os ingredientes básicos da almejada medicina personalizada.

\section{ReFERÊNCIAS}

1. Oliveira LVF.Da bancada ao leito: a partir de um diagnóstico preciso para o tratamento adequado. $\mathrm{O}$ uso crescente da pesquisa translacional.ConScientiae Saúde. 2009;8(4):545-7.

2. Lean ME, Mann JI, Hoek JA, Elliot RM, Schofield G. Translational research.BMJ. 2008;337:a863

3. Hiss RG. Fundamental issues in translational research. Translational research-two phases of a continuum. In: From clinical trials to community: The science of translating diabetes and obesity research. Proceedings from conference. January 12-13, 2004. Natcher Conference Center, National Institutes of Health, Bethesda, Maryland, USA, 2004. p. 11-4. Availablefrom: http:// www.eval.org/summerinstitute/06SIHandouts/SI06.Green. TR1.Final. pdf

4. DemeureMJ.Personalized medicine: the future is not what it used to be.Surgery;146(6):971-8.

5. Hamburg MA, Collins FS. The path to personalized medicine. NEnglJMed. 2010;363(4):301-4. Erratum in N Engl J Med. 2010;363(11):1092.

6. Swaroop A, Chew EY, Rickman CB, Abecasis GR. Unraveling a multifactorial late-onset disease: from genetic susceptibility to disease mechanisms for age-related macular degeneration. Annu Rev Genomics Hum Genet. 2009;10:19-43.

7. Schindler EI, Nylen EL, Ko AC, Affatigato LM, Heggen AC, Wang $\mathrm{K}$,et al. Deducing the pathogenic contribution of recessive ABCA4 alleles in an outbred population. Hum Mol Genet. 2010;19(19):3693-701.

8. Cideciyan AV, Swider M, Aleman TS, Tsybovsky Y, Schwartz SB, Windsor EA,et al. ABCA4 disease progression and a proposed strategy for gene therapy. Hum Mol Genet. 2009;18(5):931-41.

9. Sheffield VC, Stone EM. Genomics and the eye. N Engl J Med. 2011;364(20):1932-42.

10. Weng J, Mata NL, Azarian SM, Tzekov RT, Birch DG, Travis GH. Insights into the function of Rim protein in photoreceptors and etiology of Stargardt's disease from the phenotype in abcr knockout mice. Cell. 1999;98(1):13-23.

11. Radu RA, Han Y, Bui TV, Nusinowitz S, Bok D, Lichter J,et al. Reductions in serum vitamin A arrest accumulation of toxic retinal fluorophores: a potential therapy for treatment of lipofuscinbased retinal diseases. Invest Ophthalmol Vis Sci. 2005;46(12):4393-401. Erratumin Invest Ophthalmol Vis Sci. 2006;47(9):3735.

12. Sieving PA, Caruso RC, Tao W, Coleman HR, Thompson DJ, Fullmer KR, Bush RA. Ciliaryneurotrophic factor (CNTF) for human retinal degeneration: phase I trial of CNTF delivered by encapsulated cell intraocular implants. ProcNatlAcadSci U S A. 2006;103(10):3896-901.

13. Boatright JH, Moring AG, McElroy C, Phillips MJ, Do VT, Chang $\mathrm{B}$,et al. Tool from ancient pharmacopoeia prevents vision loss. Mol Vis. 2006;12:1706-14.

14. den Hollander AI, Black A, Bennett J, Cremers FP. Lighting a candle in the dark: advances in genetics and gene therapy of recessive retinal dystrophies. J Clin Invest. 2010;120(9):3042-53. Erratumin J Clin Invest. 2011;121(1):456-7.

15. Acland GM, Aguirre GD, Ray J,Zhang Q, Aleman TS, Cideciyan $\mathrm{AV}$, et al. Gene therapy restores vision in a canine model of childhood blindness. Nat Genet. 2001;28(1):92-5.

16. Maguire AM, Simonelli F, Pierce EA, Pugh EN Jr, Mingozzi F, Bennicelli J,et al. Safety and efficacy of gene transfer for Leber's congenital amaurosis. N Engl J Med. 2008;358(21):2240-8.Comment inN Engl J Med. 2008;358(21):2282-4.

17. Bainbridge JW, Smith AJ, Barker SS, Robbie S, Henderson R, Balaggan $\mathrm{K}$,et al. Effect of gene therapy on visual function in Leber's congenital amaurosis. N Engl J Med. 2008;358(21):22319.Comment inN Engl J Med. 2008;358(21):2282-4. 
18. Hauswirth WW, Aleman TS, Kaushal S, Cideciyan AV, Schwartz SB, Wang L,et al. Treatment of Leber congenital amaurosis due to RPE65 mutations by ocular subretinal injection of adenoassociated virus gene vector: short-term results of a phase I trial. Hum Gene Ther. 2008;19(10):979-90.

19. Chen W, Stambolian D, Edwards AO, Branham KE, Othman M, Jakobsdottir J, et al. Genetic variants near TIMP3 and high-density lipoprotein-associated loci influence susceptibility to agerelated macular degeneration. ProcNatlAcadSci U S A. 2010;107(16):7401-6.

20. Awh CC,Zanke B.Applying genetic risk data to clinical practice. Retina Today. 2011;78-9.

21. Haines JL, Spencer KM, Pericak-Vance MA. Bringing the genetics of macular degeneration into focus. ProcNatlAcadSci USA. 2007;104(43):16725-6.

22. Klein RJ, Zeiss C, Chew EY, Tsai JY, Sackler RS, Haynes C,et al. Complement factor $\mathrm{H}$ polymorphism in age-related macular degeneration. Science. 2005;308(5720):385-9.Comment in Science.2005;308(5720):362-4

23. Fagerness JA, Maller JB, Neale BM, Reynolds RC, Daly MJ, Seddon JM. Variation near complement factor I is associated with risk of advanced AMD. Eur J Hum Genet. 2009;17(1):100-4.

24. Yates JR, Sepp T, Matharu BK, Khan JC, Thurlby DA, Shahid H, Clayton DG, Hayward C, Morgan J, Wright AF, Armbrecht AM, Dhillon B, Deary IJ, Redmond E, Bird AC, Moore AT; Genetic Factors in AMD Study Group. Complement C3 variant and the risk of age-related macular degeneration. N Engl J Med. 2007;357(6):553-61.

25. Jakobsdottir J, Conley YP, Weeks DE, Ferrell RE, Gorin MB. C2 and CFB genes in age-related maculopathy and joint action with CFH and LOC387715 genes. PLoSOne. 2008;3(5):e2199.

26. Siqueira RC, Voltarelli JC, Messias AM, Jorge R. Possible mechanisms of retinal function recovery with the use of cell therapy with bone marrow-derived stem cells. ArqBras Oftalmol. 2010;73(5):474-9.
27. Lanza R, Rosenthal N. The stem cell challenge. Sci Am. 2004; 290(6):92-9.

28. Machalinska A, Baumert B, Kuprjanowicz L, Wiszniewska B, Karczewicz D, Machalinski B. Potential application of adult stem cells in retinal repair-challenge for regenerative medicine. Curr Eye Res. 2009; 34(9):748-60.

29. Otani A, Dorrell MI, Kinder K, Moreno SK, Nusinowitz S, Banin $\mathrm{E}$, et al. Rescue ofretinal degeneration by intravitreally injected adult bone marrow-derived lineage-negativehematopoietic stem cells. J Clin Invest.2004;114(6):765-74. Comment inJ Clin Invest. 2004;114(6):755-7.

30. Dahlmann-Noor A, Vijay S, Jayaram H, Limb A, Khaw PT. Current approaches and future prospects for stem cell rescue and regeneration of the retina and optic nerve.Can J Ophthalmol. 2010;45(4):333-41. Review.

31. Jonas JB, Witzens-Harig M, Arseniev L, Ho AD. Intravitreal autologous bone marrow derived mononuclear cell transplantation: a feasibility report. Acta Ophthalmol.2008;86(2):225-6.

32. Jonas JB, Witzens-Harig M, Arseniev L, Ho AD. Intravitreal autologous bone marrow-derived mononuclear cell transplantation. Acta Ophthalmol. 2010;88(4):e131-2.

33. Siqueira RC, Messias A, Voltarelli JC, Scott IU, Jorge R. Intravitreal injection of autologous bone marrow-derived mononuclear cells for hereditary retinal dystrophy: a phase I trial.Retina. $2011 \mathrm{Feb}$ 2. [Epub ahead of print].

34. Schwartz S. Sub-retinal Transplantation of hESC Derived RPE(MA09-hRPE)Cells in Patients With Stargardt's Macular Dystrophy. NCT01345006.Clinicaltrial.gov.Availablefrom: http:/ /clinicaltrials.gov/ct2/show/NCT01345006

\section{Autor correspondente:}

Rubens Camargo Siqueira

Rua Saldanha Marinho, $n^{\circ} 2815$ - sala 42

CEP 15010-100 - São José do Rio Preto(SP),Brasil

E-mail: rubenssiqueira@terra.com.br 